\title{
A Research on the Historical Origin of the Formation of "Pu Shou" Graphic Art of China
}

\author{
Yan Chang \\ Xi'an University of Science and Technology \\ Xi'an 710054, Shaanxi province, China. \\ g_ychang@163.com
}

Keywords: Pu Shou; graphic art; historical origin; formation

\begin{abstract}
Pu shou graphic art is a comprehensive embodiment of ancient animal-face decoration and sculpture art. From animal mask prototypes in the primitive society, to artifacts with animal face holding ring and unearthed rhino skulls in Yin Ruins, Anyang, Henan province, among Shang and Zhou Dynasties, to a large number of animal-face-holding-ring decorations on pottery and jade in Spring and Autumn and the Warring States periods, then to the coexistence of animal title ring on artifacts and $\mathrm{Pu}$ Shou holding ring on the doors of tombs in Qin and Han Dynasties, Pu Shouholding-ring images experienced a complete formation process. However, the archaeological data has not yet proven the exact date when the animal face holding ring evolved into the Pu shou image on doors. Therefore it can only be speculated: Before Han Dynasty, Pu Shou had been separated from decorative patterns on the artifacts, especially used for door decorations, and developed with beast-face decorations. According to the pattern formation rheological and connotation of development and change as the main clue, through the collation and analysis of the remains of primitive society to the phase of the Han Dynasty Pu Shou graphic art, clear the venation of the development, and as a basis to research the historical origin of its formation.
\end{abstract}

\section{INTRODUCTION}

There is no specific historical record about the origin of the name "Pu Shou", but physical evidence shows it was widely used on the doors in Han Dynasty, which means even before Han Dynasty, Pu Shou had already existed and used to decorate doors. It can be inferred that Pu Shou was firstly separated from the artifacts decorative patterns, and then specially used for door decorations. The objects with Pu Shou holding ring decorations include image stone (including the tomb stone, stone coffin), image brick, jade, pottery etc. Initial differentiations of Pu Shou used for door decorations are not uniform but in various shapes such as "tortoise and snake", "snails and mussels". After several years of improvement and unification, it gradually shaped Pu Shou holding ring in image stone of Han Dynasty.

\section{Animal Face Images in Primitive Society}

Some experts believe that Tao Tie image can be traced back to the Gao Miao culture period, which was at least about 7400 years before. At first only a simple shape of "Prominent mouth with tusk and three pointed crown on the mouth as well as wings of the bird on both sides of the mouth $\cdots$ it is so called the projection with a shape like Chinese character 'Ren' or a shape of Chinese character 'Jie' on the forehead of a ghost statue in Long Shan culture. This kind of projection had already appeared in the Tao Tie image in Hemudu Site culture period (fig.1). The Tao Tie images in Gao Miao culture period or later were more common with a shape of the three pointed projections" [1]. Since this argument at present is still reliable, then it can be suspected this kind of animal face pattern is also the prototype of bronze animal mask. However, it's only a partial outline, only bucktooth and prominent three tip shape are not enough to prove the complete animal 
mask graphics. The one which shows the complete image is the jade decorations of Liangzhu Culture in about 4000 years ago, and carving patterns on stone adzes in Longshan culture relics unearthed in 1963 in Liang Cheng Town in Ri Zhao, Shan Dong in China.

Liangzhu Culture distributed along the Taihu Basin about 5300-4000 years ago, from which artifacts were found with jade crown shape and jade trigeminal form. Some of them incised carved with animal face, and the others carved by concave line with decorative pattern of feathers, and relief carved with animal face. No matter characterized by concave line or shallow relief, both of them shows a striking "Double Circles" character of the two eyes in the animal face mask. Trident shaped crowns decoration also could be seen in trident shaped jade of Liangzhu culture. This pattern is very common in the Liangzhu Culture jade decoration (Fig.2), and it reached its stage of maturity. Therefore, there is a reason for us to think that it's one of the origins of the three mountains crown which later appeared on the top of the fetish.

Long Shan Culture in Shan Dong was about 4600-4000 years ago. The ornamentations on the unearthed stone axe in Liang Cheng Town, Ri Zhao, Shangdong Long Shan cultural relics were frequently found in the area. "... Marble Tomahawk, bronze axe Animal Face decoration can be traced back to the animal mask of Shandong Longshan culture including pottery with Yunlei and stone adzes engraved with Tao tie decorations on both upper sides. "[2] As Fig.3 shows this stone adzes are carved with similar but varied Animal Face decorations on both sides: similar vortex shape of the eye and prominent crest. Double circle eyes closely resemble Liangzhu Culture jade.

According to the archaeological experts, this kind of decorative patterns and forms became more mature, so they should not be at an early stage and the origin of them might be traced back even earlier. Based on Liu Dun Yuan "This kind of decoration was first seen on the potteries", [3] we may speculate that at least before the Liangzhu Culture and the Longshan culture, this kind of patterns had already appeared.

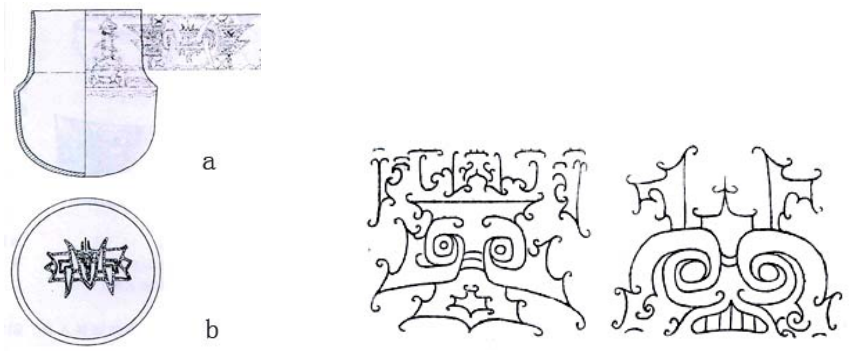

Fig.1 Image of Tao Tie of Gaomiao culture

Fig.2 Taotie patterns on stone adz

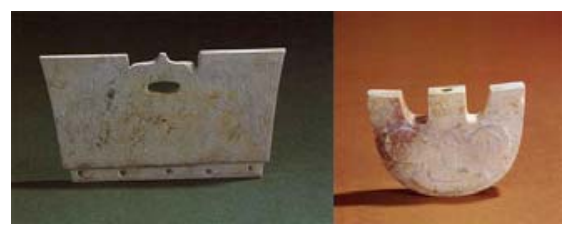

Fig.3 Ware with three heads belonging to Liangzhu culture

\section{PU SHOU PRototype OF SHANG AND ZHOU DyNASTIES}

The animal-face decoration on doors is called Pu Shou. The problem is when it is transformed into Pu Shou decorated on doors. There are door relics inheriting from Shang Dynasty, but there is no direct archaeological data for the door decorations. What is related to this is the decoration on utensils and most of them have animal-face ornamentations on the front. Mr. Zhu Qingsheng called it "the face". "The decoration on 'the face' and Tao tie are associated, to some extent, with the image of Pu Shou Holding Ring later." [4]Anyang Yin Ruins in Henan has once unearthed rhino skulls. Mr. Dingshan therefore speculated that the function of palace door decoration is to remove the ill omens. He proposed that the skull of rhino unearthed in Xiaotun which might be mounted 
onto the palace door to remove the ominous. Northern history - Ryukyu biography says that "house of the immortals must be installed with the beast heads or horns". [5] The rhino skull decoration on palace doors is the origin of "Shen tu and Yu lei", which are installed on door knockers for most palaces. In 1960s and 1970s, Chenggu in Shaanxi unearthed more than 20 pieces of bronze Pu Shou of the late Shang Dynasty. This bronze Pu Shou resemble one another in shape and size, and only slightly differ in ornamentation - resembling a cow face, central straight edge, lateral ' $\mathrm{V}$ ' shape, coarse corners, protruding eyes, ferocious image, rolls-shaped ears, convex mouth on both sides, a hole probably used to pass through or pin to other objects.[6] Because this finding has not yet been found in any other areas, Zhang Changshou hence names it as "bronze animal-face mask" rather than door decorations.

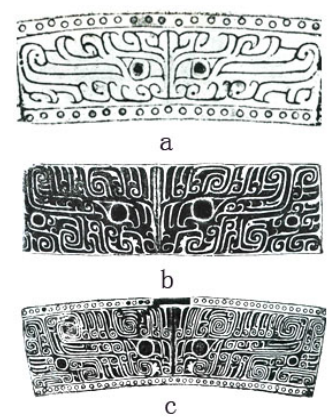

Fig.4 a. Tao Tie carved on the Jue neck at Erligang period

b. Tao Tie carved at Bronze gui abdomen in the early age of Yin Dynasty ruins time

c. Tao Tie carved at Zun abdomen in the later period of Shang Dynasty

\section{A. The Beast-face Ornamentations on the Shang Dynasty Bronze and Jade Decorations}

The development of the Animal Face decorations tended to be more advanced and mature in Shang Dynasty. At first, Er Li Gang period Animal Face decoration was confined to only simple facial features: striking eyes and nose, and the head crest was also easily identified. For example, an Animal Face decoration on JUE of Er Li Gang period (Fig.4-a), a very simplified Animal Face decoration with prominent eyes, and the top of the crown is very obvious in a three-valve shape. From the image itself, in addition to some changes in the eye, it is quite similar to the overall Liangzhu Culture jade decorative patterns. To early Shang Dynasty, Animal Face image became more complex, such as early Yin Ruins, a bronze GUI abdominal Animal Face decoration (Fig. 4-b), the decorative lines increased significantly, and on the top of the crown added the beast ears on both sides; the crown of the three valve was more obvious and increased the feathers of the decorative pattern on the sides of ears, some experts believe that is the "Yu E". By late Shang, the beast surface decoration became very complicated, and their additional decorative lines were complicated and complex, but still you can see its core image. As shown in Figure 4-C, an ox-head abdominal decorative pattern increased the number of "Yu E", middle three petaloid crest added with animal horn shaped decoration on both sides. Anyang City, Henan Province, unearthed Jade animal surface (Fig.5) of late Shang Dynasty is closer to the face of later beast face veins - generally similar to the main form of the Shang bronze animal face decoration. The jade is brown, and surface ornamentation adopts relief process. Animal face and the lower end are elliptical. Double angle in the middle has a protrusion. Eyebrow is like moiré. Head shaped eyes and binocular with large round hole. The nose is cirrus. In general, early bronze Animal Face decorative design on utensil was simple and had no shading, while late Bronze Ware Decoration was more elaborate and the patterns for Animal Face at this time has developed to great extent.

\section{B. The Animal Face Holding Ring in Shang and Zhou Dynasties}

Animal Face Holding Ring appeared in late Shang Dynasty. It was widely used in Xi Zhou Dynasty, which was basically utilized as an accessory for decorating ear-shaped handles on objects. The "ears" on the utensils were designed for the convenience of carrying or moving objects. Early ring holding image of the animal was diversified, including sheep, tiger, dragon, etc. A bronze tripod (Fig 6) of the dynasty, King Kang period (b.c.1078-b.c.1053), was unearthed in Yao Jiahe 
tomb in Lingtai County of Gansu province. This tripod has erect and slightly valgus ears, adducted foot, drum abdomen, annular bottom, four-leaf lines and round whorl around the choker, three parallel lines forming a triangular pattern at the bottom, and three epigraphs in its abdomen. It is worth noticing that the ear-shaped decorations on both sides of the tripod are very close to a tiger, and in its complete form. As can be seen from the picture, Pu Shou Holding Ring decoration in the early Xi Zhou Dynasty mounted to a more complete and mature stage. In late Xi Zhou, bronze ear decorations also had much Animal Face Holding Ring ornamentation.
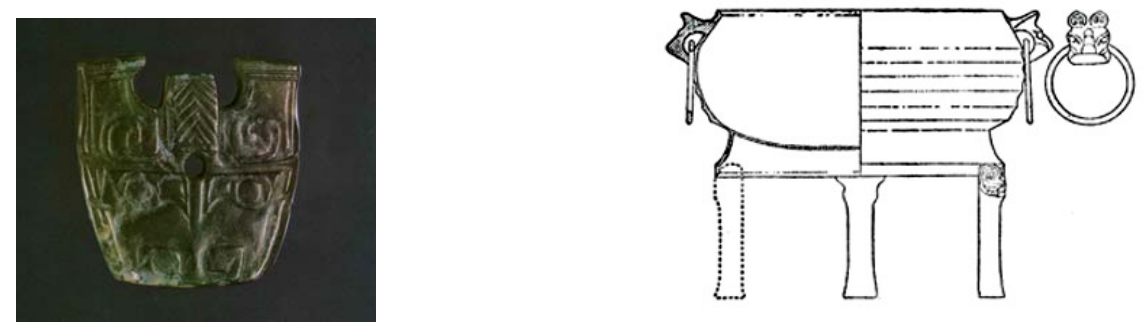

Fig.5 Jade animal face in the later period of Shang Dynasty

Fig.6 Coppery vessel at Kang King Period in East Zhou Dynasty

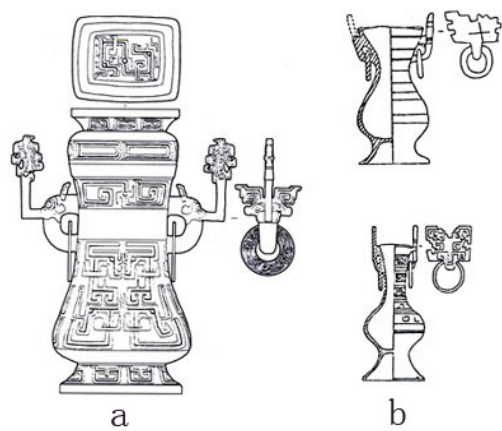

Fig.7 a.Animal Face Holding Ring at the early Spring and Autumn period

b. Animal Face Holding Ring at Ceramics pot in warring states

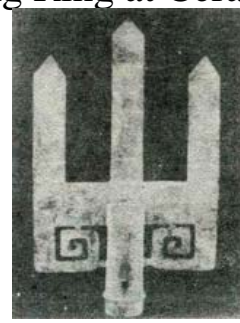

Fig.8 Coppery ware having its shape similar to SHAN character

\section{Animal Face Holding Ring Images on the Bronze W ARe, Potery AND JAde WARE in SPRING AND AUTUMN PERIODS}

During the Spring and Autumn and Warring States periods, decorative patterns on bronze wares tended to be simple. The application of Animal Face Holding Ring onto bronze decorations obviously increased, and gradually shifted its gear towards pottery and jade decoration as bronze art recessed. For example, ZENG ZHONG YOU pots of the early spring and Autumn Period (Fig.7-a) unearthed in Su Jia Long, Beijing in 1969- a lid, drum abdomen, foot; lotus-shaped lid decorated with animal face. The neck is decorated with symmetrical Animal Face Holding Ring; on top is a separate double angle; the ring is carved with regular shape of decorative patterns. Another bronze pot unearthed was found in Lixian country, Gansu province- rounded top, rectangle-circle-foot-type handle, bouffant side lid. Cross section of the body is a rounded rectangle, square lips, long neck with animal head proboscis, bird head with collar ears, vertical abdomen, flat, rounded rectangle circle foot, torus with decorative patterns. In addition, a Warring States tomb in Zhongshan unearthed a mountain-shaped bronze (Fig.8), On top of the animal face is a pair of Trident upright, swirling square eyes, which is similar to Liangzhu Culture jade Shoumian trigeminal shaped device. 
The above examples show that in the Spring and Autumn period, Animal Face Holding Ring decoration came down in one continuous fashion with the previous generations.

In the spring and Autumn period, due to the collapse of the ritual system of Shang and Zhou dynasties, the original ritual instruments descended into disorders. On the one hand, the bronze craft was still in a transitional period from a peak to a decline with the form developing from solemnity to lightweight and practicality; On the other hand, the popularization of pottery gradually began to rise to replace the production process of complex bronze and some of the daily uses of bronze. But due to the social instability in Spring and Autumn period and the Warring States periods, people could not live and work in peace and contentment, pottery making developed slowly, and therefore there are only small numbers of relics of pottery. Without any experience, the pottery of this period mostly modeled after the bronze in production. Therefore, the Animal Face Holding Ring on the bronze vessels was also applied to the pottery decoration. Southeast of Deng Jia Ya Cun, Fengxiang County, Shaanxi province unearthed Warring States period tombs with 8 pieces of pottery, among which type I and type III neck are decorated with the flat Animal Face Holding Ring (Fig.7-b). This shape is clearly modeled after a bronze kettle and its body is decorated with vermilion and white painted white cloud thunder in density. The Animal Face Holding Ring shows geometry, which is decorated with patterns.

\section{THE SUMMARY}

Initially the non-uniform shapes of Pu Shou could be an inheritance and evolution of Shang beast-mask ornamentations. Namely, after being separated from the animal mask, $\mathrm{Pu}$ Shou developed with animal-face decorations on the bronze wares, jade and pottery of Han Dynasty which also inherited the animal mask of Shang and Zhou dynasties. Therefore, it's inaccurate in some burial archaeological reports to confuse the beast holding ring at the abdomen and neck of the artifacts with Pu Shou holding ring on the door decorations. Due to the inheritance and corruption of the name "Pu Shou", modern people have been used to calling the beast holding ring on artifacts as $\mathrm{Pu}$ Shou holding ring, so the definition of $\mathrm{Pu}$ Shou which is specifically used for door decorations is gradually blurred.

\section{ACKNOWLEDGMENT}

The Project Supported by Social Science Foundation of Shaanxi Province, China (Grant No.2014I37)

\section{REFERENCES}

[1] He gang, "On Taotie and human nature in ancient China ", Southeast Culture[J], vol.7. pp. 5060,2002 .

[2] Shen Fuwei, Chinese and Western cultural exchange history[M], Shanghai people's Publishing House, pp.9,1985.

[3] Liu Dunyuan, Two stone tools found in two town sites, Archaeology[J], vol.7.pp.56, 1972.

[4] Zhu Qingsheng, The general study of the origin of God -- on misunderstanding and forming[M], Bei jing: Peking University press, pp.196. 1998.

[5] [Tang dynasty]Li Yanshou writes: Northern history - Ryukyu biography[M], Beijing: Zhonghua Book Company,pp94,1974.

[6] Wang Zijin,The door and the door god worship offerings[M], Shanghai triple Bookstore, pp $105,1996$. 